\title{
Effects of Risperidone Augmentation in Patients with Treatment-Resistant Depression: Results of Open-Label Treatment Followed by Double-Blind Continuation
}

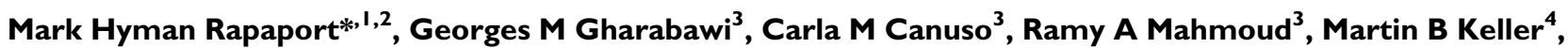 \\ Cynthia A Bossie ${ }^{3}$, Ibrahim Turkoz ${ }^{3}$, Robert A Lasser ${ }^{3}$, Amy Loescher ${ }^{3}$, Philippe Bouhours ${ }^{5}$, Fiona Dunbar ${ }^{6}$ \\ and Charles B Nemeroff ${ }^{7}$ \\ 'Department of Psychiatry, Cedars-Sinai Medical Center, Los Angeles, CA, USA; ${ }^{2}$ Department of Psychiatry, University of California, Los Angeles, \\ CA, USA; ${ }^{3}$ Medical Affairs, Janssen Pharmaceutica, Princeton, NJ, USA; ${ }^{4}$ Department of Psychiatry, Brown University, Providence, RI, USA; \\ ${ }^{5}$ Janssen-Cilag, Berchem, France; ${ }^{6}$ Janssen-Ortho Inc., Toronto, ON, Canada; ${ }^{7}$ Department of Psychiatry, Emory University Medical Center, \\ Atlanta, GA, USA
}

\begin{abstract}
Approximately one-third of persons with depression do not respond to antidepressant monotherapy. Studies suggest that atypical antipsychotic augmentation may benefit these patients. We investigated the longer-term efficacy of risperidone augmentation of serotonin-selective reuptake inhibitor treatment for resistant depression. In 57 in- and outpatient centers in three countries, we conducted a three-phase study with 4-6 weeks of open-label citalopram monotherapy, 4-6 weeks of open-label risperidone augmentation, and a 24-week double-blind, placebo-controlled discontinuation phase. A total of 489 patients with major depressive disorder and I-3 documented treatment failures entered the citalopram monotherapy phase $(20-60 \mathrm{mg} /$ day $)$. Patients with $<50 \%$ reduction in HAM-D- 17 scores entered the risperidone augmentation phase $(0.25-2.0 \mathrm{mg} /$ day). Patients with HAM-D- $17 \leqslant 7$ or CGI$\mathrm{S} \leqslant 2$ were randomized to risperidone or placebo augmentation. The primary outcome was time to relapse during the double-blind phase. During citalopram monotherapy, 434 patients had <50\% HAM-D- 17 reduction; 299 (68.9\%) were fully nonresponsive ( $<25 \%$ reduction) and 135 were partially nonresponsive (25-49\% reduction). Of the 386 nonresponders who entered the augmentation phase, 243 remitted and 241 entered the double-blind phase. Median time to relapse was 102 days with risperidone augmentation and 85 days with placebo (NS); relapse rates were 53.3 and 54.6\%, respectively. In a post hoc analysis of patients fully nonresponsive to citalopram monotherapy, median time to relapse was 97 days with risperidone augmentation and 56 with placebo $(p=0.05)$; relapse rates were 56.1 and $64.1 \%$, respectively $(p \leqslant 0.05)$. Open-label risperidone augmentation substantially enhanced response in treatment-resistant patients, but the longer-term benefits of augmentation were not demonstrated in this study.

Neuropsychopharmacology (2006) 3 I, 2505-25 I3. doi:I0. I038/sj.npp. I30 I I 3; published online 7 June 2006
\end{abstract}

Keywords: resistant depression; risperidone augmentation; citalopram

\section{INTRODUCTION}

Major depressive disorder is a common, chronic, and recurrent illness, affecting more than 320 million people worldwide (Weissman et al, 1996). It is characterized by increased medical morbidity and mortality (Tranter et al, 2002), functional impairment, reduced quality of life, substantial health-care costs, and an increased risk of suicide (Greden, 2001). The major factor contributing to this profound health burden is the extraordinarily high

\footnotetext{
*Correspondence: Dr MH Rapaport, Department of Psychiatry, Cedars-Sinai Medical Center, 8730 Alden Drive, Suite C-30I, Los Angeles, CA 90048, USA, Tel: + I 310423 2600, Fax: + I 310423 9397, E-mail: mark.rapaport@cshs.org

Received 17 June 2005; revised 27 April 2006; accepted 2 May 2006 Online publication: 10 May 2006 at http://www.acnp.org/citations/ Npp05 I 006050388/default.pdf
}

rates of relapse and recurrence associated with major depressive disorder (Robins and Regier, 1991). The results of longitudinal studies suggest that complete resolution of symptoms provides greater protection against relapse (Solomon et al, 2004; Fava et al, 2004). Therefore, the psychiatric community has identified complete symptom resolution and relapse prevention as the primary treatment goals for patients with major depressive disorder (American Psychiatric Association, 2000).

Although initial antidepressant therapy significantly reduces symptoms of depression in many patients, only $50-60 \%$ of patients with major depressive disorder respond to treatment (Nierenberg and DeCecco, 2001). Moreover, between 30 and $40 \%$ of persons who suffer from major depressive disorder never achieve symptom resolution with standard antidepressant therapy (Amsterdam and HornigRohan, 1996; Nierenberg and Amsterdam, 1990). This has 
stimulated a comprehensive search for more effective treatment alternatives (Keller, 2005). However, the term 'treatment-resistant depression' is used inconsistently in the literature as well as in protocols for randomized clinical studies. Definitions have varied widely as treatmentresistant depression encompasses a broad continuum of severity and complexity. In fact, proposed staging criteria for treatment-resistant depression range from failure to respond to an adequate trial (dose and duration) of a single antidepressant to failure to respond to multiple classes of antidepressants, as well as electroconvulsive therapy (Thase and Rush, 1995, 1997; Ananth, 1998).

Currently, there is no evidence-based algorithm to guide treatment for patients whose depression has been poorly responsive to one or more standard therapies. There is a general consensus, however, that potential options include (1) augmentation with psychotherapy (De Jonghe et al, 2004), (2) switching classes of medication (McGrath et al, 1993), (3) supplementation with a second antidepressant of a different class (Bodkin et al, 1997; Gomez Gomez and Teixido Perramon, 2000), (4) somatic therapy such as rapid transcranial magnetic stimulation, electroconvulsive therapy, or vagal-nerve stimulation (Figiel et al, 1998; Rush et al, 2000; Wahlund and von Rosen, 2003), and (5) augmentation strategies with agents usually not considered as classical antidepressants, such as lithium (Fava, 2001) or thyroid hormone (Joffe et al, 1993). One augmentation strategy that has recently been explored is supplementation of antidepressants with atypical antipsychotic medications (Ostroff and Nelson, 1999; Shelton et al, 2001; Adson et al, 2004; Papakostas et al, 2004).

At this time, only one large-scale trial evaluating atypical antipsychotic augmentation in treatment-resistant depression has been published, and there are no large doubleblind data regarding the benefits of any type of continued augmentation treatment for patients with resistant depression (Shelton et al, 2005). These gaps in knowledge served as the impetus for this 9-month international study designed to evaluate the effect of long-term augmentation treatment with risperidone in patients with confirmed treatment-resistant depression. We sought to determine whether short-term open-label risperidone augmentation of a serotonin-selective reuptake inhibitor (SSRI) reduces depressive symptomatology in treatment-resistant patients and whether continuation treatment with risperidone augmentation provides greater maintenance of effect than a return to antidepressant monotherapy. Our primary hypothesis was that continuation augmentation treatment with risperidone would reduce relapse rates more than placebo treatment.

\section{METHODS}

Augmentation with Risperidone in Resistant Depression (ARISe-RD) is a large international study conducted at 57 sites in the USA, Canada, France, and the UK from June 2002 to January 2004. It was approved by the institutional review board/ethics committee for each site and written informed consent was obtained from each subject. This 9-month prospective study included three phases: (1) 4-6 weeks of open-label citalopram monotherapy to confirm nonresponse to a standard SSRI; (2) 4-6 weeks of open-label risperidone treatment to evaluate the augmentation effects relative to SSRI monotherapy and to identify patients with symptom resolution; and (3) a 24-week double-blind discontinuation phase to assess the effect of augmentation with risperidone $v s$ placebo in the prevention of relapse. Subjects who met criteria for relapse in this third phase were offered open-label risperidone augmentation for the duration of the trial.

\section{Patient Population}

Subjects were in- or outpatients, aged 18-85 years, meeting Diagnostic and Statistical Manual of Mental Disorders, 4th edition (DSM-IV) diagnostic criteria for major depressive disorder, single or recurrent episode, with or without psychotic features, and with a Hamilton Rating Scale for Depression (Hamilton, 1960) (HAM-D-17) total score $\geqslant 20$. The diagnoses were made at each site by experienced clinicians based on a comprehensive assessment of the patient. However, a structured diagnostic interview was not performed. Subjects were required to have a history of resistance to standard antidepressant therapy, defined as failure to respond to at least one but not more than three adequate antidepressant trials during the current episode (at least 6 weeks at a dose of antidepressant medication within the ranges approved by the Food and Drug Administration for the treatment of depression). Comorbid anxiety disorders other than obsessive-compulsive disorder were not grounds for exclusion. All other DSM-IV axis 1 diagnoses, including dementia and bipolar disorder (type I or II) as well as a lifetime diagnosis of DSM IV borderline personality disorder, were exclusion criteria.

All subjects received a complete medical history, physical examination, laboratory evaluation, including chemistry panel, liver panel, complete blood count, urine analysis, and urine pregnancy test (for women), toxicology screening, and electrocardiography. Subjects who were medically healthy and those who had stable medical conditions were eligible to participate in the study.

\section{Study Design}

The design of this three-phase study is shown in Figure 1.

Open-label citalopram monotherapy: In the open-label citalopram monotherapy phase, flexible dosing was initiated at $20 \mathrm{mg} /$ day. The citalopram dose was increased based on clinical efficacy and side effects. The clinicians were requested to try to achieve a target dose of $60 \mathrm{mg} /$ day for patients aged 18-54 years and $40 \mathrm{mg}$ /day for those aged 55-85 years. The citalopram monotherapy treatment period was 6 weeks (or 4 weeks for patients who were unchanged or worse at that point). Patients who were nonresponders $(<50 \%$ reduction in HAM-D-17 total scores) at the end of citalopram monotherapy were eligible to enter the risperidone augmentation phase of the study.

Open-label risperidone augmentation: The open-label risperidone augmentation phase was 4-6 weeks in duration (at the discretion of the investigator, patients who demonstrated clinical improvement but had not yet achieved symptom resolution could be treated for 6 weeks). Patients who achieved symptom resolution, defined as a HAM-D-17 
Citalopram Monotherapy

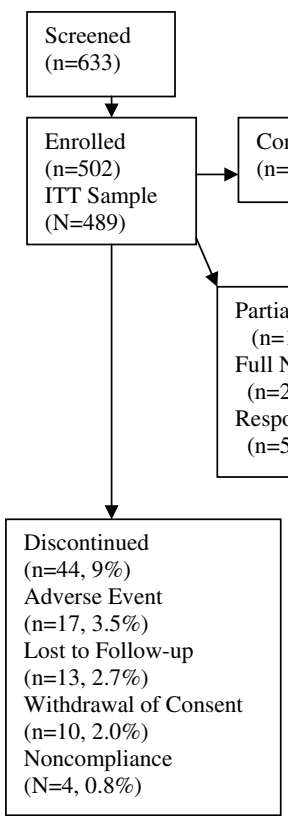

Risperidone Augmentation

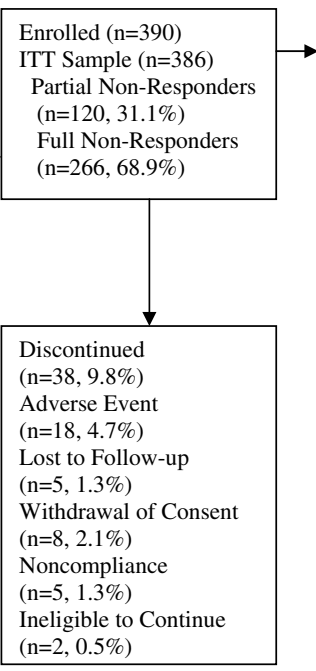

Double-Blind Maintenance

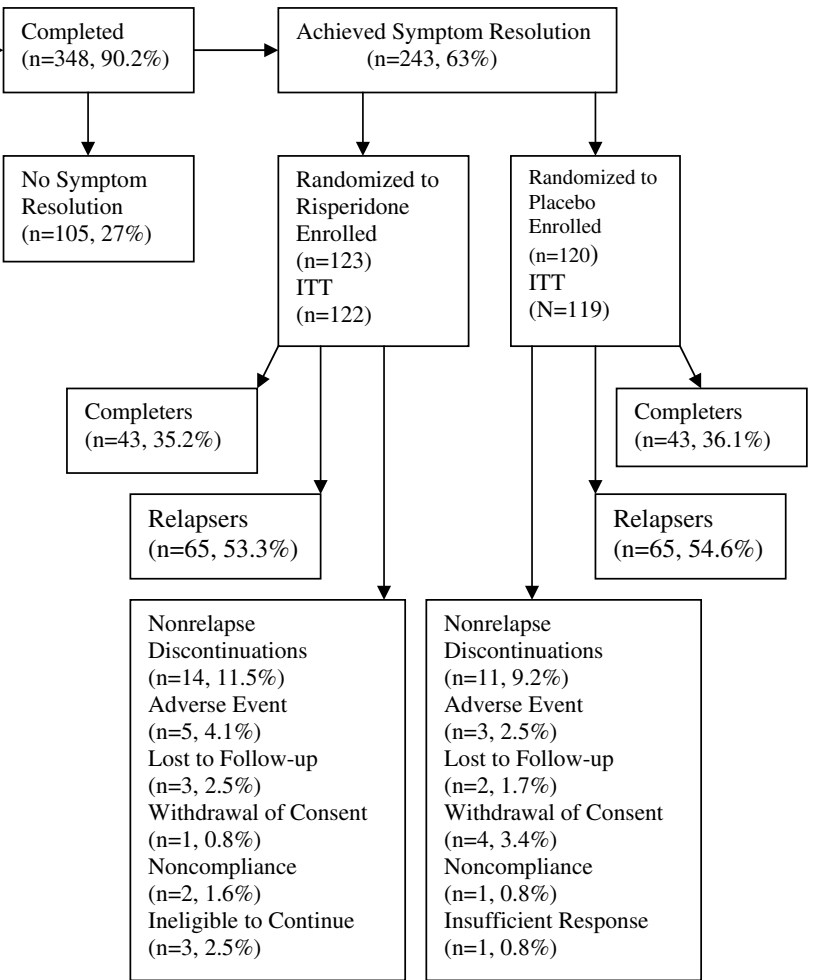

Figure I Study design and patient flow.

score $\leqslant 7$ or Clinical Global Impressions-Severity (CGI-S) score of 1 (not ill) or 2 (borderline ill) (Guy, 1976), with risperidone augmentation were eligible to enter the doubleblind continuation phase. Citalopram was continued at the same dose achieved at the end of the monotherapy period. The risperidone augmentation dose was initiated at $0.5 \mathrm{mg} /$ day and targeted to $1 \mathrm{mg} /$ day $(0.5-2.0 \mathrm{mg} /$ day permitted) for patients aged 18-54 years and initiated at $0.25 \mathrm{mg} /$ day and targeted to $0.5 \mathrm{mg} /$ day $(0.25$ or $1 \mathrm{mg} /$ day permitted) for patients aged 55-85 years.

Double-blind continuation phase: In the 24-week doubleblind phase, patients were randomized to continue on risperidone plus citalopram or to receive placebo plus citalopram. The primary outcome was time to relapse, defined as any one or more of these four criteria: (1) CGIChange (CGI-C) score of 6 (much worse) or 7 (very much worse); (2) HAM-D-17 total score $\geqslant 16$; (3) discontinuation owing to lack of therapeutic effect; or (4) deliberate selfinjury or suicidal intent. Patients who met relapse criteria during the double-blind treatment phase of the study were eligible to receive open-label risperidone and continue assessments for the remainder of the 24-week study period. At the end of the 24-week double-blind study period, patients were either tapered off study medication over 2 weeks or continued in a 3-month aftercare program.

Additional psychotropic medications were excluded during the entire study, with the exception of lorazepam or an equivalent benzodiazepine for agitation or restlessness during the citalopram monotherapy phase. Zolpidem, zaleplon, or zopiclone could be used to treat the symptoms of insomnia during any phase of the study.

\section{Outcome Measures}

Efficacy assessments included clinician-rated scales designed to measure symptoms of depression and overall clinical status. The Montgomery-Asberg Depression Rating Scale (MADRS) (Montgomery and Asberg, 1979), a 10-item scale that assesses a range of depressive symptoms, was the primary outcome measure used to assess depression severity. The HAM-D-17 evaluates depressed mood as well as the neurovegetative and cognitive symptoms of depression. In this study, the HAM-D-17 was employed as a screening tool to determine subject eligibility for the three phases of the study and as one relapse criterion during the double-blind discontinuation phase. The MADRS and HAM-D-17 were completed during the open-label citalopram monotherapy phase (baseline, weeks 2, 4, and 6 ), the open-label risperidone augmentation phase (baseline, day 4, weeks $1,2,4$, and 6), and the double-blind phase (baseline, weeks 2, 4, 8, 12, 16, 20, and 24). The CGI$\mathrm{S}$ scale measures global severity of illness at a given point in time, whereas the CGI-C measures the change in the patient's clinical status. The CGI-S ratings were obtained during the open-label citalopram monotherapy (baseline, end point), the risperidone augmentation phase (baseline, day 4 , weeks $1,2,4$, and 6 ), and the double-blind phase (baseline, weeks 8, 16, and 24). CGI-C ratings were obtained during the double-blind phase (weeks 2, 4, 8, $12,16,20$, and 24 ). Other scales assessing anxiety, quality of life, sexual functioning, resource utilization, and cognition were also administered. Their results will be presented elsewhere. 
Safety assessments included reports of spontaneous adverse events collected at every visit. Vital signs, electrocardiograms (ECGs), and laboratory test results were obtained at scheduled visits. The Abnormal Involuntary Movement Scale (AIMS; for dyskinesia and dystonia) (Guy, 1976), the Simpson-Angus Rating Scale (SAS; for parkinsonism) (Simpson and Angus, 1970), and the Barnes Akathisia Scale (BAS) (Barnes, 1989) were completed at regular intervals to measure movement disorders.

\section{Randomization and Blinding}

A statistician independent of the study generated randomization sequences. The randomization was noncentralized and stratified by site, age (18-54 and 55-85 years), and presence of psychotic features. The blinded treatment codes were assigned using an automated interactive voice response system. The integrity of the double blind was maintained through database lock.

\section{Statistical Methods}

A power analysis was based on an estimated relapse rate of $35 \%$ in the risperidone group and $55 \%$ in the placebo group, indicating that the number of observed relapses required to have a $90 \%$ chance of detecting a constant hazard ratio of 0.54 was approximately 110 , at the $5 \%$ significance level with a two-sided test. Thus, it was estimated that a total of approximately 234 subjects, 117 in each group with 1:1 randomization ratio, would yield adequate statistical power to detect differences in the double-blind phase. Assuming that approximately $10 \%$ of the subjects would not complete the study owing to reasons other than relapse, the total number of planned subjects was increased to 260 .

The safety population consisted of all enrolled subjects who had received at least one dose of study medication. The efficacy population for each phase consisted of all enrolled subjects who had received at least one postbaseline efficacy assessment. The last available evaluation for each patient defined the end-point analyses (last observation carried forward). Analysis of covariance, with treatment and center as independent factors and baseline score as covariate, was used to compare treatments on continuous variables. Categorical variables were evaluated using the Cochran-Mantel-Haenzel test stratifying by site. Time to relapse was compared between groups using Kaplan-Meier survival curves. A post hoc analysis using linear rank tests (weighted log-rank test) was performed because of a violation of the proportional hazards assumptions of the preplanned survival analysis (Kaplan-Meier survival curves intersected). Further post hoc analyses were performed assessing the subgroup of patients whom we considered fully nonresponsive $(<25 \%$ improvement) to open-label citalopram monotherapy (Fava and Davidson, 1996). A Cox regression model was used to assess the impact of level of response (full or partial) to citalopram monotherapy on subsequent relapse in the double-blind phase. Uncorrected $t$-statistics was used to compare adverse events in the two patient groups.

\section{RESULTS}

\section{Patient Flow and Baseline Characteristics}

Of the 633 patients who gave their written informed consent and were screened, 489 entered the citalopram monotherapy phase of the study. Of the 144 patients who did not enter this phase, $54 \%$ did not meet entry criteria, $23 \%$ withdrew consent, $10 \%$ were lost to follow-up, and $13 \%$ were withdrawn for a variety of unspecified administrative reasons. Baseline characteristics are shown in Table 1. Subjects were predominantly female and white with a mean $( \pm S D)$ age of $46.3 \pm 12.6$ years. The mean duration of illness was $16.2 \pm 12.7$ years and duration of the current episode was $2.0 \pm 4.2$ years. Sixty-five percent of subjects were treated with two or more antidepressants within the current episode. Two percent of subjects had psychotic features. Baseline HAM-D-17 $(25.1 \pm 3.5)$ and MADRS $(31.8 \pm 5.0)$ scores reflect substantial symptom severity. The citalopram monotherapy phase was completed by 445 (91.0\%) of the patients. Reasons for discontinuation are shown in Figure 1. Four hundred and thirty-four $(88.8 \%)$ patients were nonresponders to open-label citalopram monotherapy $(<50 \%$ reduction in HAM-D-17 scores at end point); 299 $(68.9 \%)$ were fully nonresponsive $(<25 \%$ HAM-D-17 score reduction); and $135(31.1 \%)$ were partially nonresponsive (25-49\% HAM-D-17 score reduction).

Three hundred and eighty-six patients entered the openlabel risperidone augmentation phase. Their clinical and demographic characteristics were similar to those at study baseline (Table 1). This phase was completed by 348 (90.2\%) patients; reasons for discontinuation are shown in Figure 1. With risperidone augmentation, 243 (63.0\%) achieved symptom resolution (HAM-D-17 score $\leqslant 7$ or CGI-S score of 1 or 2). Of the 241 patients who entered the double-blind placebo-controlled continuation phase, $63.1 \%$ had been fully nonresponsive to open-label citalopram and $36.9 \%$ had been partially nonresponsive. Discontinuations for reasons other than relapse are shown in Figure 1. Overall, clinical and demographic characteristics of subjects entering the double-blind phase were similar to those at study entry (Table 1).

Mean ( \pm SD) modal doses were $46.0 \pm 15.8 \mathrm{mg} /$ day of citalopram during the citalopram monotherapy phase; $52.6 \pm 11.1 \mathrm{mg} /$ day of citalopram and $1.1 \pm 0.6 \mathrm{mg} /$ day of risperidone during the open-label risperidone augmentation phase; and $53.1 \pm 10.5 \mathrm{mg} /$ day of citalopram and $1.2 \pm 0.6 \mathrm{mg} /$ day of risperidone during the double-blind continuation phase.

\section{Efficacy Outcome Measures}

Open-label citalopram monotherapy and risperidone augmentation: Mean MADRS total scores were significantly reduced at each time point and at end point during the citalopram monotherapy phase. The left side of Figure 2 shows the MADRS change score for all patients and for the $88.8 \%$ of citalopram nonresponders who were eligible to enter the risperidone augmentation phase. The right side of Figure 2 shows that the MADRS total scores were significantly reduced from day 4 to end point in the 386 patients who entered the risperidone augmentation phase; 
Table I Demographic and Baseline Characteristics of Patients Entering Each Study Phase (Safety Population)

Double-blind

\begin{tabular}{|c|c|c|c|}
\hline $\begin{array}{l}\text { Open-label citalopram } \\
\text { monotherapy }(N=500)\end{array}$ & $\begin{array}{l}\text { Open-label risperidone } \\
\text { augmentation }(N=388)\end{array}$ & $\begin{array}{l}\text { Risperidone } \\
\text { augmentation }(N=122)\end{array}$ & $\begin{array}{l}\text { Placebo augmen } \\
(N=119)\end{array}$ \\
\hline$N(\%)$ & N (\%) & N (\%) & N (\%) \\
\hline $46.3 \pm 12.6$ & $47.0 \pm 12.6$ & $47.8 \pm 11.4$ & $48.4 \pm 12.0$ \\
\hline 464 (92.8\%) & $360(92.8 \%)$ & II 3 (92.6\%) & III (93.3\%) \\
\hline 345 (69.0\%) & 265 (68.3\%) & 87 (7I.3\%)* & $67(56.3$ \\
\hline
\end{tabular}

Race

White

Hispanic

Black

Oriental

Other
Age at onset of major depression

(mean \pm SD)

Duration of illness (years)

(mean \pm SD)

Patients diagnosed as MDD without psychotic features

$$
\begin{array}{r}
448(89.6 \%) \\
25(5.0 \%) \\
14(2.9 \%) \\
5(1.0 \%) \\
8(1.6 \%)
\end{array}
$$

$\begin{array}{ll}35.9 \pm 12.9 & 30.6 \pm 14.1 \\ 16.2 \pm 12.7 & 16.5 \pm 12.7 \\ 480(98.2 \%) & 379(98.2 \%)\end{array}$

$350(90.2 \%)$

$18(4.6 \%)$

I ( $(2.8 \%)$

$4(1.0 \%)$

$5(1.3 \%)$

$379(98.2 \%)$
$113(92.6 \%)$
$87(71.3 \%)^{*}$

$$
\begin{gathered}
\text { I| } 4 \text { (93.4\%) } \\
6(4.9 \%) \\
\text { I }(0.8 \%) \\
\text { | }(0.8 \%) \\
0
\end{gathered}
$$

$29.9 \pm 12.6$

$17.9 \pm 12.3$

$121(99.2 \%)$
105 (88.2\%)

$4(3.4 \%)$

$2(1.7 \%)$

$3(2.5 \%)$

$30.8 \pm 14.0$

$17.6 \pm 13.9$

II $15(96.6 \%)$

Number of depressive episodes in the last 12 months

$\begin{array}{lcr}\text { One } & 430(87.9 \%) & 338(87.6 \%) \\ \text { Two } & 45(9.2 \%) & 38(9.8 \%) \\ >\text { Two } & 13(2.6 \%) & 10(2.6 \%)\end{array}$

$38(87.6 \%)$

$10(2.6 \%)$

$$
\begin{gathered}
105(86.1 \%) \\
13(10.7 \%) \\
4(3.3 \%)
\end{gathered}
$$

$2.0 \pm 3.6$

$174(45.1 \%)$

$$
2.0 \pm 3.7
$$$$
54(44.3 \%)
$$

$103(86.6 \%)$

$13(10.9 \%)$

$3(2.5 \%)$

Current episode

Mean duration (years) (mean $\pm \mathrm{SD}$ )

$229(44.8 \%)$

episode duration $>$ I year

Previous antidepressant treatment (current episode)

$\begin{array}{lr}\text { One antidepressant } & 161(32.9 \%) \\ \text { Two or more antidepressants } & 320(65.4 \%) \\ \text { Missing } & 8(1.6 \%)\end{array}$

$$
\begin{gathered}
119(30.8 \%) \\
26 \mid(67.6 \%) \\
6(1.6 \%)
\end{gathered}
$$

$$
\begin{gathered}
35(28.7 \%) \\
85(69.7 \%) \\
2(1.6 \%)
\end{gathered}
$$

5 । $(43.9 \%)$

Number of hospitalizations for depression since onset

$\begin{array}{lcccc}\text { None } & 352(72.0 \%) & 28 \mid(72.8 \%) & 81(66.4 \%) & 90(75.6 \%) \\ \text { One } & 75(15.3 \%) & 60(15.5 \%) & 23(18.9 \%) & 14(11.8 \%) \\ >\text { One } & 61(12.5 \%) & 45(11.7 \%) & 18(14.8 \%) & 15(12.6 \%)\end{array}$

$* p<0.05$ vs placebo.

mean $( \pm$ SD) scores were reduced from $27.7 \pm 7.2$ at baseline to $13.2 \pm 10.1$ at end point $(p<0.001)$. Mean MADRS and HAM-D 17 scores are shown in Table 2.

Double-blind placebo-controlled risperidone augmentation: The Kaplan-Meier median time to relapse was 102 days with continued risperidone augmentation and 85 days with placebo augmentation ( $p=0.52$, log-rank) (Figure 3 ). The rate of relapse was $53.3 \%$ in the risperidone augmentation group and $54.6 \%$ in the placebo augmentation group.
As reported above, an alternative post hoc statistical method using linear rank tests (weighted log-rank test) was used to compare survival curves in order to regain the originally defined statistical power level. This analysis suggested a difference in time to relapse in favor of risperidone-treated patients $(p<0.05)$. Investigators reported that significant increases in HAM-D-17 and CGI-C scores were the most common criteria for relapse in both the risperidone and placebo augmentation groups (overall, 90.0 and $87.7 \%$, 


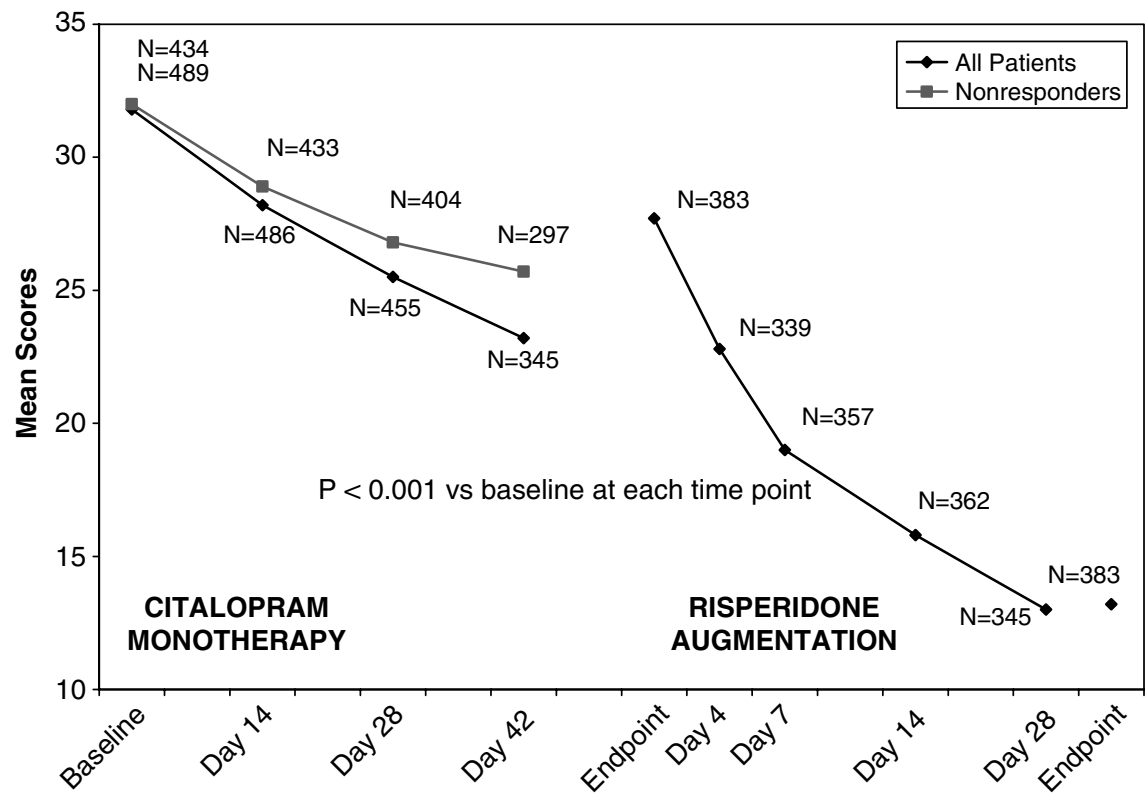

Figure 2 MADRS total scores during citalopram monotherapy and risperidone augmentation.

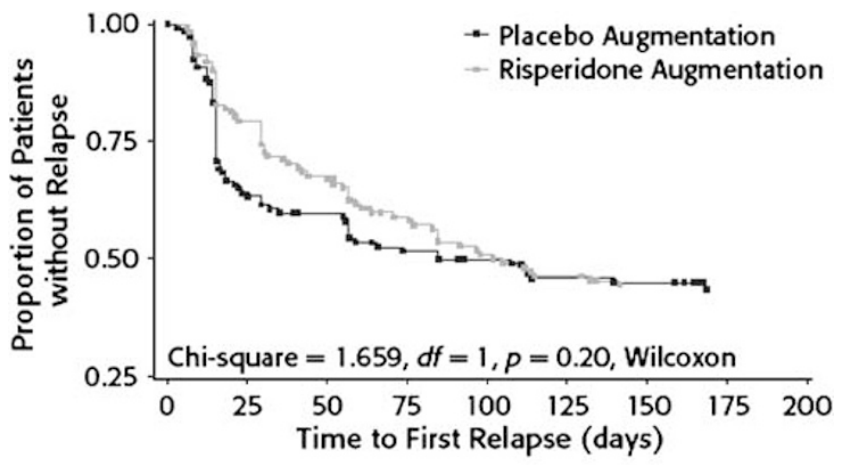

$\begin{array}{lllllllllll}\text { Placebo: } & & & & & & & & & & \\ \mathrm{N}= & 119 & 74 & 67 & 55 & 50 & 45 & 44 & 14 & 1 \\ \text { Risperidone: } & & & & & & & \end{array}$

$\begin{array}{llllllllll}\mathrm{N}= & 122 & 94 & 79 & 65 & 55 & 50 & 44 & 25 & 2\end{array}$

Figure 3 Kaplan-Meier estimates of the time to relapse in the total patient group. respectively). Mean MADRS and HAM-D 17 scores are shown in Table 2.

An additional post hoc subgroup analysis was performed on the data of the 152 patients who were fully nonresponsive to citalopram monotherapy $(<25 \%$ reduction in HAMD-17 total score). In these patients, the Kaplan-Meier median time to relapse was 97 days with risperidone augmentation and 56 days with placebo augmentation $(p=0.05$, Wilcoxon; Figure 4$)$. The relapse rate was $56 \%$ in the risperidone group and $64 \%$ in the placebo group $(p=0.05)$. Among the 89 patients who were partially nonresponsive to citalopram $(25-<50 \%$ reduction in HAM-D-17 total score), there was no difference in the Kaplan-Meier estimate in time to relapse $(p=0.54$, Wilcoxon). A regression analysis explored the impact of full $v s$ partial nonresponse to open-label citalopram on subsequent relapse during the double-blind phase. Results of the Cox regression model revealed a hazard ratio of 1.6

Table 2 Mean Depression Rating Scale Scores

Double-blind

Open-label citalopram monotherapy $(N=489)$
Open-label risperidone augmentation $(N=383)$

\begin{tabular}{cc}
\hline Risperidone & Placebo augmentation \\
augmentation $(N=\mid 22)$ & $(N=I 19)$
\end{tabular}

augmentation $(N=122)$
$8.1 \pm 4.6$

$10.4 \pm 11.2^{\dagger}$

\section{MADRS total}

Baseline score

End-point change

HAM-D 17 total

Baseline score

End-point change

\section{$31.8 \pm 5.0$}

$-6.3 \pm 8.7$ *
$27.7 \pm 7.2$

$-14.5 \pm 9.6 *$
$6.8 \pm 4.7$

$11.2 \pm 12.6^{\dagger}$
$21.4 \pm 5.2$

$-|1| \pm$.6.9 *
$6.3 \pm 2.9$

$6.0 \pm 3.0$

$7.9 \pm 8.1^{\dagger}$

${ }^{*} p<0.01,{ }^{\dagger} p<0.001$ change score vs baseline. 
$(p=0.014)$, suggesting that patients who were fully nonresponsive to citalopram were much more likely to relapse during the double-blind phase than those who were partial nonresponders.

Among the 130 patients who fulfilled relapse criteria during the double-blind phase, $110(84.6 \%)$ elected to resume open-label treatment with risperidone. Overall, $50 \%$ again met the criteria for symptom resolution; results did not differ significantly as a function of treatment condition during the double-blind phase (risperidone, $45 \%$; placebo, $54 \% ; p=0.34$ by $\chi^{2}$ ).

\section{Safety Outcome Measures}

Adverse event rates are presented in Table 3 for all three phases of the study. The types and frequency of adverse

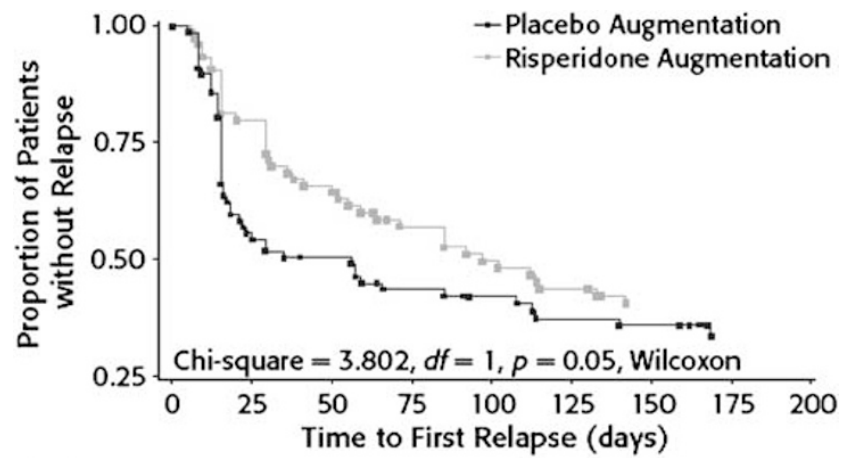

$\begin{array}{llllllllll}\text { Placebo: } & & & & & & & & \\ \mathrm{N}= & 77 & 42 & 37 & 30 & 27 & 24 & 23 & 4 & 0 \\ \begin{array}{l}\text { Risperidone: } \\ \mathrm{N}=\end{array} & 75 & 57 & 47 & 38 & 33 & 29 & 24 & 15 & 2\end{array}$

Figure 4 Kaplan-Meier estimates of the time to relapse in the fully resistant patients. events reported are consistent with previous reports in the literature and were usually judged to be mild in severity. There were no clinically significant changes in mean SAS, BAS, or AIMS scores in any study phase and no significant between-group differences in the double-blind period. No clinically meaningful changes in vital signs or ECGs were noted during the study. The only potentially clinically meaningful laboratory abnormality was the mean $( \pm S D)$ prolactin level at end point: $35.4 \pm 53.4 \mathrm{ng} / \mathrm{ml}$ in the risperidone group $v s 6.6 \pm 21.0 \mathrm{ng} / \mathrm{ml}$ in the placebo group $(p<0.001)$. Galactorrhea was reported in $2.5 \%$ of risperidone-treated patients but none of the placebo-treated subjects. The proportion of patients who gained $7 \%$ or more of their body weight from baseline to end point of each phase was $1.3 \%$ in citalopram monotherapy; $3.1 \%$ in risperidone augmentation; and 8.3 and $2.6 \%$ in the risperidone augmentation and placebo augmentation groups, respectively. The mean weight change during the double-blind phase was $1.3 \pm 3.8 \mathrm{~kg}$ with risperidone augmentation and $-0.5 \pm 2.9 \mathrm{~kg}$ with placebo augmentation.

\section{DISCUSSION}

This is one of two large placebo-controlled studies of treatment augmentation with an atypical antipsychotic in patients with treatment-resistant depression that have been published (Shelton et al, 2005), and the only controlled study to date investigating the efficacy of atypical antipsychotic augmentation for continuation treatment of resistant depression. The primary finding from the openlabel phase of this study suggests that risperidone augmentation is associated with symptom resolution for a significant number of patients who were nonresponsive to a prospective adequate trial with citalopram. The rapid reduction in MADRS scores (Figure 2) during this

Table 3 Most Commonly Reported Adverse Events (5\% or More of Patients in Any Group; Safety Population)

\begin{tabular}{|c|c|c|c|c|c|}
\hline \multirow[b]{3}{*}{ Adverse event } & \multirow{3}{*}{$\begin{array}{c}\begin{array}{c}\text { Open-label citalopram } \\
\text { monotherapy }(N=500) \\
N(\%)\end{array}\end{array}$} & \multirow{3}{*}{$\begin{array}{c}\text { Open-label risperidone } \\
\text { augmentation }(N=388) \\
N(\%)\end{array}$} & \multicolumn{3}{|c|}{ Double-blind } \\
\hline & & & $\begin{array}{c}\text { Risperidone } \\
\text { augmentation }(N=122)\end{array}$ & $\begin{array}{l}\text { Placebo augmentation } \\
\qquad(N=I 19)\end{array}$ & Exact prob. ${ }^{\mathbf{a}}$ \\
\hline & & & $N(\%)$ & $N(\%)$ & \\
\hline Headache & $97(19.4)$ & $45(11.6)$ & $14(1 \mid .5)$ & $7(5.9)$ & 0.17015 \\
\hline Nausea & $55(11.0)$ & $19(4.9)$ & $4(3.3)$ & $4(3.4)$ & 1.00000 \\
\hline Dry mouth & $45(9.0)$ & $49(12.6)$ & $2(1.6)$ & $3(2.5)$ & 0.68099 \\
\hline Insomnia & $40(8.0)$ & II (2.8) & $4(3.3)$ & $7(5.9)$ & 0.37153 \\
\hline Somnolence & $35(7.0)$ & $32(8.2)$ & $3(2.5)$ & $4(3.4)$ & 0.71970 \\
\hline Diarrhea & $33(6.6)$ & $19(4.9)$ & $5(4.1)$ & $4(3.4)$ & 1.00000 \\
\hline Dizziness & $27(5.4)$ & $33(8.5)$ & $7(5.7)$ & $3(2.5)$ & 0.33372 \\
\hline Constipation & $19(3.8)$ & $19(4.9)$ & $4(3.3)$ & $4(3.4)$ & 1.00000 \\
\hline Fatigue & $16(3.2)$ & $10(2.6)$ & $6(4.9)$ & $9(7.6)$ & 0.43512 \\
\hline Tremor & II (2.2) & $30(7.7)$ & $4(3.3)$ & $2(1.7)$ & 0.68369 \\
\hline Weight increase & $10(2.0)$ & $24(6.2)$ & $9(7.4)$ & $5(4.2)$ & 0.41033 \\
\hline Appetite increase & $9(1.8)$ & $22(5.7)$ & $2(1.6)$ & $3(2.5)$ & 1.00000 \\
\hline
\end{tabular}

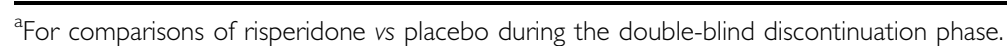


augmentation phase is similar to that seen in previous smaller studies of atypical antipsychotic augmentation of SSRI-resistant depression (Ostroff and Nelson, 1999; Shelton et al, 2001, 2005; Adson et al, 2004; Papakostas et al, 2004). The precipitous decline in MADRS scores with risperidone augmentation is not what one would anticipate if this merely reflected an increased exposure to a few more weeks of antidepressant monotherapy (Rapaport et al, 2004). These open-label observations do require confirmation with double-blind placebo-controlled trials.

An important finding from the double-blind phase of the study is that continuation of augmentation with risperidone does not seem to confer significant additional benefit beyond short-term treatment (Figure 3). Consistent with observed rates of relapse, there was also a worsening in mean depression rating scale scores in both groups (Table 2). However, for patients who respond partially to citalopram treatment, brief periods of augmentation may be sufficient to enable them to overcome an impasse in response to SSRI treatment. Such findings are analogous to the use of short-term corticosteroid augmentation therapy in asthma, Crohn's disease, and ulcerative colitis.

Another clinically important, albeit exploratory, observation from this study is that 110 of 130 patients who relapsed during the double-blind discontinuation phase elected to enter an open-label stabilization retrieved-dropout component of the study. This suggests that the patients believed that they benefited from risperidone augmentation. Approximately $50 \%$ of these patients remitted with flexibledose open-label augmentation therapy.

Secondary analyses suggest that among the patients who were fully nonresponsive to citalopram monotherapy, risperidone augmentation was associated with a statistically and potentially clinically meaningful delay in the time to relapse (Figure 4). The percentage advantage over placebo treatment is similar to that reported by Robert and Montgomery (1995) in patients randomized to continuation treatment with citalopram. As previously noted, this observation requires further evaluation in a well-controlled prospectively designed study.

Data from our longer-term trial of an atypical antipsychotic augmentation of an SSRI in treatment-resistant depression indicate that risperidone augmentation is generally safe and well tolerated (Table 3 ). There were no unexpected adverse events reported and those reported were similar in the two augmentation groups. Treatment with risperidone augmentation was associated with serum prolactin elevations, but few reports of clinically associated adverse events were evident. A small number of subjects had a greater than $7 \%$ increase in body weight over the course of the study. Finally, ratings of motor side effects were low throughout the trial, suggesting minimal risk of movement disorders. It is important to note that the doses of risperidone used in this study were significantly lower than those typically used for the treatment of schizophrenia or bipolar mania.

One limitation of the study design is the open-label nature of the lead-in phases. The citalopram monotherapy nonresponse rate in this study was higher than that suggested in previously published reports (Einarson, 2004; Thase et al, 2001). Although rater or patient bias may have influenced the open-label results, an alternative explanation may be the chronicity and severity of illness of these patients resulting in this low rate of response. Moreover, according to our definition of initial nonresponse during the citalopram monotherapy phase, patients who were partially as well as fully nonresponsive to citalopram were included. Although this only represents a small subset of subjects, this may have influenced findings in the double-blind phase of this study. A second limitation is that a structured diagnostic interview was not part of the initial assessment of subjects. This may have resulted in less uniformity in diagnosis. However, entry into this study required a clinical assessment by an experienced clinician. A third possible criticism of this study is the relatively brief initial period of citalopram monotherapy. We had to balance ethical concerns about the continued exposure of patients with resistant depression to a monotherapy that was clearly not benefiting them with ideal scientific rigor. We felt that a 4- to 6-week initial phase was a reasonable trial for patients who had not previously responded to an average of two other medication trials.

This study is the first large augmentation continuation trial in treatment-resistant depression and may suggest the need to consider alternative designs. Treatment-resistant depression tends to have a complex waxing and waning course. A single-event definition of relapse may not adequately model 'true' relapse for patients who suffer a recurrent illness with fluctuating symptoms. It may well be that a measurement that captures 'total days well' may be a more clinically meaningful outcome to employ for studies of patients with resistant major depression. Another design feature that might allow a more clinically relevant approach to investigating efficacy during the continuation phase of therapy would be the use of a flexible-dose strategy during the double-blind phase. Only subjects who meet relapse criteria despite assertive manipulation of the double-blind compound would be classified as having a relapse. This approach would more closely approximate what usually occurs in clinical practice.

In conclusion, treatment-resistant depression is a common challenge that clinicians and patients must face. In this large international multicenter study, two-thirds of the patients responded rapidly and robustly to open-label risperidone augmentation. This supports previously published open-label studies investigating augmentation with a number of atypical antipsychotic medications (Shelton et al, 2001; Adson et al, 2004; Papakostas et al, 2004). A recent double-blind study of olanzapine augmentation in acutely ill patients showed a rapid but less robust response (Shelton et al, 2005), demonstrating the need for replication of the risperidone findings in a prospective double-blind placebocontrolled clinical trial. A second important finding from this trial is that some patients may benefit from a brief period of augmentation, as $50 \%$ of the patients who entered the placebo arm of the double-blind phase remained relapse-free. This suggests that treatment-resistant depression is a heterogeneous entity and that a variety of different treatment approaches may be needed to ensure that a patient receives the most appropriate care. Our secondary analysis revealed that patients who were least responsive to citalopram monotherapy may be those most likely to benefit from continuation therapy with risperidone. This post hoc finding bears replication but may serve as a potential 
indicator of which subgroup of patients with treatmentresistant depression requires longer-term augmentation therapy. In general, results of the present study demonstrate that risperidone augmentation of citalopram is a reasonable and safe strategy that is helpful for some patients with treatment-resistant major depressive disorder.

\section{ACKNOWLEDGEMENTS}

This research was funded by Medical Affairs, Janssen Pharmaceutica, LP. MH 61757-A2, 1R21 AT002751-01, 1R01 MH73765-01A1, Cedars-Sinai GCRC Grant RR00425 and The Polier Endowed Chair for Schizophrenia and Related Disorders were supported MHR.

\section{REFERENCES}

Adson DE, Kushner MG, Eiben KM, Schulz SC (2004). Preliminary experience with adjunctive quetiapine in patients receiving selective serotonin reuptake inhibitors. Depress Anxiety 19: 121-126.

American Psychiatric Association (2000). Practice guideline for the treatment of patients with major depressive disorder. Am J Psychiat 157: 1-45.

Amsterdam JD, Hornig-Rohan M (1996). Treatment algorithms in treatment-resistant depression. Psychiatr Clin N Am 19: 371-386.

Ananth J (1998). Treatment-resistant depression. Psychother Psychosom 67: 61-70.

Barnes TR (1989). A rating scale for drug-induced akathisia. Br J Psychiat 154: 672-676.

Bodkin JA, Lasser RA, Wines Jr JD, Gardner DM, Baldessarini RJ (1997). Combining serotonin reuptake inhibitors and bupropion in partial responders to antidepressant monotherapy. J Clin Psychiat 58: 137-145.

De Jonghe F, Hendricksen M, van Aalst J, Kool S, Peen V, Van R et al (2004). Psychotherapy alone and combined with pharmacotherapy in the treatment of depression. Br J Psychiat 185: 37-45.

Einarson TR (2004). Evidence based review of escitalopram in treating major depressive disorder in primary care. Int Clin Psychopharmacol 19: 305-310.

Fava GA, Ruini C, Rafanelli C, Finos L, Conti S, Grandi S (2004). Six-year outcome of cognitive behavior therapy for prevention of recurrent depression. Am J Psychiat 161: 1872-1876.

Fava M (2001). Augmentation and combination strategies in treatment-resistant depression. J Clin Psychiat 62(Suppl 18): 4-11.

Fava M, Davidson KG (1996). Definition and epidemiology of treatment-resistant depression. Psychiatr Clin N Am 19: 179-2000.

Figiel GS, Epstein C, McDonald WM, Amazon-Leece J, Figiel L, Saldivia A et al (1998). The use of rapid-rate transcranial magnetic stimulation (rTMS) in refractory depressed patients. J Neuropsychiat Clin Neurosci 10: 2025.

Gomez Gomez JM, Teixido Perramon C (2000). Combined treatment with venlafaxine and tricyclic antidepressants in depressed patients who had partial response to clomipramine or imipramine: initial findings. J Clin Psychiat 61: 285-289.

Greden JF (2001). The burden of disease for treatment-resistant depression. J Clin Psychiat 62(Suppl 16): 26-31.

Guy W (1976). ECDEU Assessment Manual for Psychopharmacology: Publication ADM 76-338. US Department of Health, Education, and Welfare: Washington, DC. pp 218-222.

Hamilton M (1960). A rating scale for depression. J Neurol Neurosurg Psychiat 23: 56-62.

Joffe RT, Singer W, Levitt AJ, MacDonald C (1993). A placebocontrolled comparison of lithium and triiodothyronine augmentation of tricyclic antidepressants in unipolar refractory depression. Arch Gen Psychiat 50: 387-393.

Keller MB (2005). Issues in treatment-resistant depression. J Clin Psychiat 66(Suppl 8): 5-12.

McGrath PJ, Stewart JW, Nunes EV, Ocepek-Welikson K, Rabkin JG, Quitkin FM et al (1993). A double-blind crossover trial of imipramine and phenelzine for outpatients with treatmentrefractory depression. Am J Psychiat 150: 118-123.

Montgomery SA, Asberg M (1979). A new depression scale designed to be sensitive to change. Br J Psychiat 134: 382-389; 592.

Nierenberg AA, Amsterdam JD (1990). Treatment-resistant depression: definition and treatment approaches. J Clin Psychiat 51(Suppl): 39-47; discussion 48-50.

Nierenberg AA, DeCecco LM (2001). Definitions of antidepressant treatment response, remission, nonresponse, partial response, and other relevant outcomes: a focus on treatment-resistant depression. J Clin Psychiat 62(Suppl 16): 5-9.

Ostroff RB, Nelson JC (1999). Risperidone augmentation of selective serotonin reuptake inhibitors in major depression. J Clin Psychiat 60: 256-259.

Papakostas GI, Petersen TJ, Nierenberg AA, Murakami JL, Alpert JE, Rosenbaum JF et al (2004). Ziprasidone augmentation of selective serotonin reuptake inhibitors (SSRIs) for SSRI-resistant major depressive disorder. J Clin Psychiat 65: 217-221.

Rapaport MH, Bose A, Zheng H (2004). Escitalopram continuation treatment prevents relapse of depressive episodes. J Clin Psychiat 65: 44-49.

Robert P, Montgomery SA (1995). Citalopram in doses of 20-60 mg is effective in depression relapse prevention: a placebocontrolled 6 month study. Int Clin Psychopharmacol 10(Suppl 1): 29-35.

Robins LN, Regier DA (1991). Psychiatric Disorders in America: The Epidemiologic Catchment Area Study. Free Press: New York.

Rush AJ, George MS, Sackeim HA, Marangell LB, Husain MM, Giller C et al (2000). Vagus nerve stimulation (VNS) for treatment-resistant depressions: a multicenter study. Biol Psychiat 47: 276-286.

Shelton RC, Tollefson GD, Tohen M, Stahl S, Gannon KS, Jacobs TG et al (2001). A novel augmentation strategy for treating resistant major depression. Am J Psychiat 158: 131-134.

Shelton RC, Williamson DJ, Corya SA, Sanger TM, Van Campen $\mathrm{LE}$, Case $\mathrm{M}$ et al (2005). Olanzapine/fluoxetine combination for treatment-resistant depression: a controlled study of SSRI and nortriptyline resistance. J Clin Psychiat 66: 1289-1297.

Simpson GM, Angus JW (1970). A rating scale for extrapyramidal side effects. Acta Psychiatr Scand Suppl 212: 11-19.

Solomon DA, Leon AC, Endicott J, Mueller TI, Coryell W, Shea MT et al (2004). Psychosocial impairment and recurrence of major depression. Compr Psychiat 45: 423-430.

Thase ME, Feighner JP, Lydiard RB (2001). Citalopram treatment of fluoxetine nonresponders. J Clin Psychiat 62: 683-687.

Thase ME, Rush AJ (1995). Treatment resistant depression. In: Bloom FE, Kupfer DJ (eds). Neuropsychopharmacology: The Fourth Generation of Progress. Raven Press: New York. pp 1081-1097.

Thase ME, Rush AJ (1997). When at first you don't succeed: sequential strategies for antidepressant nonresponders. J Clin Psychiat 58(Suppl 13): 23-29.

Tranter R, O'Donovan C, Chandarana P, Kennedy S (2002). Prevalence and outcome of partial remission in depression. J Psychiat Neurosci 27: 241-247.

Wahlund B, von Rosen D (2003). ECT of major depressed patients in relation to biological and clinical variables: a brief overview. Neuropsychopharmacology 28(Suppl 1): S21-S26.

Weissman MM, Bland RC, Canino GJ, Faravelli C, Greenwald S, Hwu HG et al (1996). Cross-national epidemiology of major depression and bipolar disorder. JAMA 276: 293-299. 